\title{
FRACTURE STUDIES ON SYNTHETIC FIBER REINFORCED CELLULAR CONCRETE USING ACOUSTIC EMISSION TECHNIQUE
}

\author{
Abdur Rasheed, $\mathrm{M}^{1}$, Suriya Prakash. $\mathrm{S}^{2}$, Gangadharan Raju ${ }^{3}$, Yuma Kawasaki ${ }^{4}$ \\ ${ }^{1}$ Research Scholar, Email: ce13m15p100001@iith.ac.in \\ ${ }^{2}$ Associate Professor and Corresponding Author, Email: suriyap@iith.ac.in \\ ${ }^{3}$ Assistant Professor, Email: gangadharanr@iith.ac.in \\ Department of Mechanical and Aerospace Engineering, IIT-Hyderabad, Telangana, India \\ ${ }^{4}$ Associate Professor, Email: yuma-k@fc.ritsumei.ac.jp \\ Department of Civil Engineering, Ritsumeikan University, Shiga, Japan
}

\begin{abstract}
Cellular lightweight concrete (CLC) is increasingly used for low strength non-structural and structural applications. The effects of synthetic fiber reinforcement on the fracture behavior of CLC is investigated. In particular, acoustic emission (AE) technique is employed to study the influence of macro (structural), micro polyolefin synthetic fibers and their combinations on the fracture behavior of CLC beams. Notched fiber reinforced CLC beams were tested to study the crack initiation and propagation characteristics using AE sensors. Different AE parameters are correlated with the crack growth and damage accumulation. An attempt has been made to correlate the crack mouth opening displacement (CMOD) with the number of AE hits. The variation of cumulative acoustic energy release of the cracks is studied with respect to applied load and CMOD. Three dimensional source location of cracks is carried out based on the AE events picked by the sensors bonded to the CLC specimens. The analysis of AE results indicates that the crack source location identification from $\mathrm{AE}$ is consistent with the actual crack development. Analysis of AE signals reveal that the CLC matrix cracking produces signals with less number of hits that lie in the notched plane in bending. Moreover, the signals from the post peak regime correspond to more number of hits which tend to be scattered around the plane of notch due to the fiber pull out.
\end{abstract}

Keywords: Acoustic Emission; Crack propagation; Fracture Behavior; Health Monitoring; Hybrid Fibers; Non-destructive testing; Polyolefin fibers; 


\section{INTRODUCTION}

34 Cellular lightweight concrete (CLC) is increasingly used in various low strength structural and non-structural applications due to its properties like low density, termite resistance, high thermal and acoustic insulation [1]. CLC is widely used in infill masonry construction, soil stabilisation, solid fills for hollow aluminium doors and window frames, thermal insulation on roof slabs, and in tunnel linings [2], [3]. Moreover, CLC can be classified as sustainable and green building material due to the usage of high volume of fly ash during the manufacturing process [4]. The low carbon footprint involved in manufacture of CLC makes it an eco-friendly building material. However, the low tensile strength and brittle nature of CLC raises concerns when subjected to flexure, tensile and shear loading and limits its different applications. years due to its ability to transform the brittle behavior of CLC into ductile under various modes of testing such as compression, flexure, tension, shear and impact [5]. Fiber reinforced CLC (FRCLC) is one such special concrete which has enhanced toughness, better composite behavior, durability and impact resistance compared to their unreinforced counterpart [6], [7]. Improvement of mechanical properties of high performance concrete by addition of synthetic fiber reinforcement has been confirmed by many researchers [8]-[12]. Although steel fibers have superior mechanical properties compared to that of synthetic fibers, they decrease the workability and creates a balling effect at higher dosage. On the other hand, structural synthetic fibers, being non-corrosive and malleable, have gained attention in the recent years. They are also used for reinforcing cementitious materials to control the crack propagation and improve the overall structural performance [8], [9]. Synthetic plastic fibers used in this study are not green and a sustainable mateiral. Use of natural fibers may be a sustainable option. 
This is relatively a low proportion compared to the volume of the matrix. In addition, recycled plastic wastes can also be used as fiber reinforcement in CLC. Besides, the synthetic fibers used in this study have well defined mechanical properties, which the natural fibers and other recycled fibers lack. Therefore, to reduce the variability in the experimental program, synthetic fibers with relatively low dosages are used. Polyolefin fibers used in this study comes under the category of synthetic fibers. They are manufactured in two different types (a) Monofilament and (b) fibrillated. Monofilament fibers have constant cross sectional area along its length. Fibrillated fibers are produced as films or tapes which can transform like net when mixed with concrete. Synthetic Polyolefin fibers can also be classified as micro or macro (structural) fibers. Micro-synthetic fibers are typically $12 \mathrm{~mm}$ long and $0.018 \mathrm{~mm}$ in diameter. Macro ones are typically longer $(40$ to $50 \mathrm{~mm})$ and larger $(0.3$ to $1.5 \mathrm{~mm})$ in size. Better bonding characteristics is now possible by the virtue of surface improvement on the fiber. Low density, better corrosion resistance and chemical inertness makes synthetic fibers a better choice for FRC when compared to the steel fibers. However, the low modulus of elasticity of synthetic fibers restricts them to be used as primary reinforcement. Nevertheless, these fibers can be used for special applications like cold storage walls, slab on-grade, ballast less subgrade track, tunnel linings and non-load bearing precast partition walls in high rise framed structures/ load bearing walls of appropriate thickness in low rise buildings [13]. Therefore, it is important to understand the effect of fiber reinforcement on the fracture behavior of CLC to increase its wide spread usage.

Fracture parameters for CLC has been investigated in the past [14]. Indirect tensile strength, strain softening and fracture energy of different types of aerated autoclaved concrete (AAC) has also been reported [15]. Crack nucleation is a phenomenon where cracks at micro scale coalesce to from a macro crack, which eventually leads to the failure of concrete under flexure. The three dimensional region where this process happens is referred to as fracture 
process zone (FPZ) [16]. In particular, acoustic emission (AE) technique is used to quantitatively assess the crack growth in structural elements by correlating it with the AE hits encountered. It can be argued that the pores in the cellular concrete can hinder the propagation of elastic waves emanating from the crack source, thereby weakening the signal strength. This is true in case of porous concrete materials where the matrix media is predominantly disconnected. Whereas in cellular concrete material, the pore structure is disconnected. This makes the CLC medium continuous and does not hinder the wave propagation.

Attempts have been made in the past to qualitatively define the damage accumulation in concrete using acoustic emission (AE) technique [17]. Berthelot et al. [18] performed frequency analysis on concrete specimens to identify AE events by deducing its spectrum from detected signal. Sause and Stefan [19] modelled AE crack source using finite element modelling approach which calculates the dynamic displacement field during crack formation. Landis and Shah [20] conducted experimental study on flexural behavior of mortar beams to evaluate micro-crack parameters using AE technique. They found that the predominant mode of fracture in micro-cracks of mortar is mode II. Recent study has confirmed that AE activity increases with the amount of steel fiber reinforcement [21]. Qualitative fatigue crack classification on reinforced concrete beams was studied by Noorsuhada et al. [22]. Two indices of $\mathrm{AE}$ parameters were used and the relationship indicated the transition of crack mode corresponding to the damage development. Hu et al. [23] conducted fracture tests on notched concrete beams and illustrated that AE technique can be employed effectively to determine the crack propagation until the complete failure of specimen. In addition, they also noted that $\mathrm{AE}$ technique could help in obtaining the initial fracture load and unstable load at a slow loading rate. Cracking due to corrosion has been detected and located [24]-[30] using AE technique. Aggelis et al. [31] conducted the shear and tensile fracture test on cementitious materials by 
altering the loading equipment. It was observed that different modes of fracture process can be identified using AE technique. Aldahdooh and Bunnori [32] tested reinforced concrete beams under flexure and showed that the initial level of damage was associated with the tensile mode and gradually shifted towards shear mode of failure with increase in damage levels. The test results from $\mathrm{AE}$ technique has also been verified by researchers [33]-[35] using digital image correlation (DIC) technique. The focus of this investigation is to understand the fracture behavior of FRCLC under flexure. Notched FRCLC specimen were tested under three-point bending configuration with AE sensors attached on the surfaces. Generally, the AE sensors can range from $5 \mathrm{kHz}$ upto $2000 \mathrm{kHz}$. Studies from past reveals that for studying normal concrete narrow band sensors are sufficient. However, since the CLC material has been investigated using AE sensors for the first time, the authors wanted to make sure that, any higher frequency wave is not eliminated by the use of only narrow band sensors. Finally, the analysis of the results shows that the average frequency lies in the range of $50 \mathrm{kHz}$ to $350 \mathrm{kHz}$. Therefore, usage of two different kind of sensors results in overlap of frequency range of $200 \mathrm{kHz}$ with a difference of $\pm 50 \mathrm{kHz}$. Crack formation modes can be distinguished into shear and tensile modes based on the two methods viz., Parameter based method and simplified Green function for moment tensor analysis (SiGMA) procedure [36].

In the recent years, continuous monitoring of structures in-service has been highlighted around the world. Thus, development of non-destructive evaluation (NDE) techniques for the inspection of concrete structures is currently in high demand. Varieties of innovative NDE techniques are actively under development in concrete engineering, which are closely associated with fracture mechanics. Fracture in a material takes place with the release of stored strain energy, which is consumed by nucleating new external surfaces (cracks) and emitting elastic waves. The latter phenomenon is defined as acoustic emission (AE). The elastic waves propagate inside a material and are detected by an AE sensor. By analyzing the detected signals, 
more useful information associated with the damage location and extent of internal damage can be assessed successfully. Thus, the AE technique can be a viable non-destructive and reusable tool compared to the conventional mechanical testing for health monitoring. In this way, the authors believe that with proper calibration and in-depth scientific reasoning, AE technique can be an indispensable tool for non-destructive evaluation of new sustainable materials such as fiber reinforced CLC explored in this study.

\section{RESEARCH SIGNIFICANCE}

Number of investigation in the past have focused on understanding the behavior of fiber reinforced concrete using $\mathrm{AE}$ technique. However, the acoustic emission behavior of fiber reinforced CLC has not been adequately investigated in the past. To fill in the existing knowledge gap, the current study aims at the following: (i) study the fracture parameters of fiber reinforced CLC material under flexure, (ii) qualitative analysis of various AE parameters for the corresponding crack initiation and propagation in CLC, (iii) quantification of damage accumulation by studying the crack growth against the cumulative acoustic emission counts and (iv) identification of fracture process zone (FPZ) using AE source location and differentiating the type of failure modes by correlating AE parameters with crack mouth opening displacement (CMOD).

\section{EXPERIMENTAL PROGRAM}

\subsection{Materials}

The material ingredients used for casting CLC consisted of ordinary Portland cement (OPC), class F-flyash, potable water and foaming agent (Table 1). Design mix proportions used for achieving a characteristic density of $950 \pm 20 \mathrm{~kg} / \mathrm{m}^{3}$ are given in Table 1 . Water-binder ratio is kept constant at 0.38 , considering the fly ash also acts as binder. Fiber dosage of $5 \mathrm{~kg} / \mathrm{m}^{3}$ is 
kept as the upper value based on the observed stress strain behaviour under compression. For a particular batch of specimen, the amount of fiber is added in addition to control mixture proportion. For instance, the addition of fiber for $0.55 \%$ volume fraction is $5 \mathrm{~kg}$ of fibers per cubic meter of concrete. The volume fraction of fiber is very less compared to the total volume of the mix. Therefore, the impact of addition of fiber in the mix proportion volume was found to be negligible on workability. CLC mix used in this study does not have any aggregates. The mix contained only cement, fly ash, foaming agent, water and different dosages of fibers. Therefore, the mix remained in liquid state even after adding fibers. Patty tests showed the spread was more than $500 \mathrm{~mm}$ even at addition of higher fiber dosages of $0.55 \%$. CLC mix used in the study flowed into the moulds like self-compacting concrete and remained unaffected by addition of fibers. It showed equally good mobility into the moulds even after addition of high volume of fiber dosages. Improved workability tests like slump flow test and flowability test on CLC with different fiber dosages would be interesting and are scope for further work.

Fly ash procured from national thermal power plant corporation (NTPC) is used in the CLC mix. It had a minimum of $20 \%$ of fines for obtaining the optimum strength to weight ratio. Organic content and other impurities in the fly ash were found to be within tolerance limits. Siliceous fly ash of class $\mathrm{F}$ is used and its basic chemical composition is provided in Table 2. OPC 53 grade is used in the preparation of CLC mix. For early demolding of CLC blocks, high early strength cements can also be used as suggested by IS 2185 Part 4 [37]. However, it has been observed that slower the hardening rate, the better will be the final quality of CLC blocks. The addition of fly ash serves as an economical substitute for cement, reduces its shrinkage, and slows down the hardening rate of the mix. Keeping in view of all these requirements, OPC is used with the fly ash in the ratio of 1:3. 
TABLE 1. List of proportions $\left(\mathrm{kg} / \mathrm{m}^{3}\right)$ in Design Mix

\begin{tabular}{|c|c|c|c|c|}
\hline Component & Cement & Flyash & Water & Foam \\
\hline Proportion $\left(\mathrm{kg} / \mathrm{m}^{3}\right)$ & 277 & 715 & 277 & 1.4 \\
\hline
\end{tabular}

184

185

186

TABLE 2. Basic chemical composition of Class F fly ash

\begin{tabular}{|c|c|c|c|c|c|c|c|}
\hline Component & $\mathrm{SiO}_{2}$ & $\mathrm{Al}_{2} \mathrm{O}_{3}$ & $\mathrm{CaO}$ & $\mathrm{Fe}_{2} \mathrm{O}_{3}$ & $\mathrm{MgO}$ & Alkalies & $\begin{array}{c}\text { Organic } \\
\text { impurities }\end{array}$ \\
\hline $\begin{array}{c}\text { Proportion } \\
(\%)\end{array}$ & $50-60$ & $24-27$ & $6-8$ & $10-13$ & 1 & 1.5 & $3-4$ \\
\hline
\end{tabular}

Maintaining the stability of foam is essential for achieving the desired density of CLC mix and to have a closed pore structure. Protein hydrolyzed foaming agents impart the desired characteristics to the foam generated. For the purpose of this study, a commercially available foaming agent was used. Foaming agent and water was mixed in a ratio of 1:40 and fed into foam generator to achieve a density of $70 \mathrm{~g} /$ litre of the pre-formed foam. The volume fraction of foam in the mix is $16 \%$ of the total volume. Total volume of the pores in the CLC is $35 \%$. Care has to be taken that the water or foaming agent should not come into contact with oily/waxy agents due its harmful effect on the surface tension of water. This could destroy the pore structure of CLC mix, thereby reducing the stability of the foam. Oil/wax used for coating the moulds will have no effect on the CLC mix, as the foam will already get embedded in the mortar at that stage.

Test series with one control and seven different specimen series with different dosage of macro and hybrid-synthetic polyolefin fibers (Figure 1) were prepared. Properties of macro and micro fibers are given in Table 3 . The plain concrete mix contains no fibers. FRCLC mix had macro (ma) polypropylene fiber contents equal to $0.22 \%, 0.33 \%, 0.44 \%$ and $0.55 \%$ respectively. Similarly, hybrid fiber (macro + micro(mi)) dosage consists of the following combinations $0.22 \% \mathrm{ma}+0.02 \% \mathrm{mi} ; 0.33 \% \mathrm{ma}+0.02 \% \mathrm{mi}$ and $0.44 \% \mathrm{ma}+0.02 \% \mathrm{mi}$, 

each fiber dosage.

207

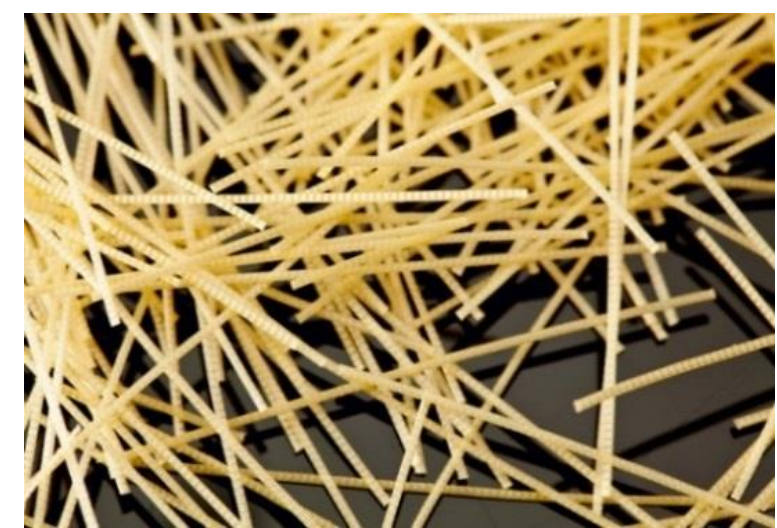

(a) Macro fiber

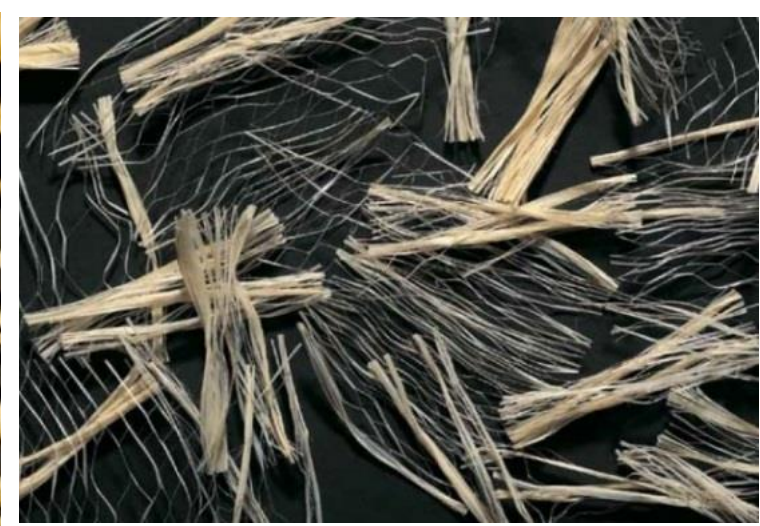

(b) Micro fiber

Figure 1: Polyolefin fiber

Auxiliary specimens like cylinders of dimension $200 \mathrm{~mm}$ height and $100 \mathrm{~mm}$ diameter were

cast in addition during casting process and tested to determine the behavior under compression.

Similarly, dog-bone shaped specimens were tested under uni-axial tension. Summary of compression and tension test results is given in Table 4. Compression toughness index (CTI) and tension toughness index (TTI) values were calculated from the area under stress-strain curves from the respective tests. Therefore, the unit of TTI and CTI will be those of energy per unit volume that is $\mathrm{N}-\mathrm{mm}$ per cubic millimeter which turns out to be MPa. Complete details of uniaxial compression and tension tests and results can be found elsewhere [8], [10].

TABLE 3. Characteristics of the synthetic fibers 


\begin{tabular}{|c|c|c|}
\hline & Macro & Micro \\
\hline Specification & Bi-component fiber & Inter-linked fiber \\
\hline Length $(\mathrm{mm})$ & 50 & 19 \\
\hline Diameter $(\mathrm{mm})$ & 0.5 & 0.08 \\
\hline Density $\left(\mathrm{g} / \mathrm{cm}^{3}\right)$ & 0.91 & 0.91 \\
\hline Tensile Strength $\left(\mathrm{N} / \mathrm{mm}^{2}\right)$ & 618 & 400 \\
\hline Tensile Modulus $\left(\mathrm{kN} / \mathrm{mm}^{2}\right)$ & 10 & 4.9 \\
\hline Aspect ratio & 100 & 237.5 \\
\hline Shape & Oval & Circle \\
\hline Decomposition Temp $\left({ }^{\circ} \mathrm{C}\right)$ & 360 & 360 \\
\hline
\end{tabular}

TABLE 4. Test Results of CLC under Compression and Tension with and without Fibers

\begin{tabular}{|c|c|c|c|c|c|}
\hline Series & Specimen & $\begin{array}{c}\text { Mean } \\
\text { Compressive } \\
\text { Strength } \\
\text { (Standard } \\
\text { Deviation) MPa }\end{array}$ & $\begin{array}{c}\text { CTI } \\
\left(10^{-3} \mathrm{MPa}\right)\end{array}$ & $\begin{array}{c}\text { Mean Tensile } \\
\text { Strength } \\
\text { (Standard } \\
\text { Deviation) MPa }\end{array}$ & $\begin{array}{c}\text { TTI } \\
\text { (MPa) }\end{array}$ \\
\hline I & Control & $3.89(0.30)$ & 6.99 & $0.13(0.37)$ & 0.16 \\
\hline \multirow{2}{*}{$\begin{array}{c}\text { II } \\
\text { (only } \\
\text { macro) }\end{array}$} & ma-0.22-mi-0.00 & $5.94(0.92)$ & 47.20 & $0.21(0.32)$ & 30.2 \\
\cline { 2 - 6 } & ma-0.33-mi-0.00 & $6.16(0.98)$ & 54.90 & $0.32(0.73)$ & 47.9 \\
\cline { 2 - 6 } & ma-0.44-mi-0.00 & $6.58(0.52)$ & 66.00 & $0.36(0.34)$ & 58.1 \\
\cline { 2 - 6 } III & ma-0.55-mi-0.00 & $6.49(0.71)$ & 63.50 & $0.44(0.18)$ & 85.5 \\
\cline { 2 - 6 } (hybrid) & ma-0.11-mi-0.02 & $3.91(0.15)$ & 57.55 & - & - \\
\cline { 2 - 6 } & ma-0.22-mi-0.02 & $6.67(0.84)$ & 68.27 & $0.28(0.14)$ & 34.6 \\
\cline { 2 - 6 } & ma-0.33-mi-0.02 & $8.39(0.90)$ & 72.13 & $0.34(0.25)$ & 52.5 \\
\cline { 2 - 6 } & ma-0.44-mi-0.02 & $8.44(1.40)$ & 78.46 & $0.41(0.25)$ & 63.6 \\
\hline
\end{tabular}

\section{Note:}

I. More details on compression and tension test results on CLC can be found in other paper of authors [8], [10]

II. ma- macro fiber; mi- micro fiber; $0.11,0.22,0.33,0.44,0.55$ - volume fraction of fibers in $\%$. CTI -Compressive toughness index, TTI- Tension toughness index.

\subsection{Test Setup}

Different codal provisions are available for determination of fracture energy of concrete under flexure. RILEM committee report [38] has given recommendations for performing the fracture test on notched concrete specimens under flexure. Based on these recommendations, EN 14651:2005 [39] and JCI [40] standards has given test procedures for determination of fracture parameters of concrete. For the purpose of this study, flexural testing was conducted on notched beams as per the guidelines given in EN 14651:2005 [39]. CLC beams of size 600 
$\times 200 \times 150 \mathrm{~mm}$ were tested in the three-point bending configuration. A notch of $50 \mathrm{~mm}$ depth and $5 \mathrm{~mm}$ width was introduced at the mid-span using a circular saw as per the guidelines given in EN 14651 [39]. The flexure test was conducted in a crack mouth opening displacement control mode at a rate of $0.05 \mathrm{~mm} / \mathrm{min}$. A photograph of the test setup is shown in Figure 2.

\subsection{Fracture Energy}

Fracture energy $\left(\mathrm{G}_{\mathrm{F}}\right)$ is the measure of energy absorbed by the specimen to undergo a unit area of crack formation through a predefined path. The area of crack is defined as the projected area on the plane parallel to main crack direction. The fracture energy of FRCLC were calculated using the guidelines provided in JCI-S-001-2003 [40]. The equations used for calculation of fracture energy are listed below.

$$
G_{F}=\frac{0.75 W_{o}+W_{1}}{A_{\text {lig }}}
$$

$$
W_{1}=0.75\left(\frac{s}{L} m_{1}+2 m_{2}\right) g \cdot C M O D_{C}
$$

where $\mathrm{G}_{\mathrm{F}}=$ Fracture Energy $\left(\mathrm{N} / \mathrm{mm}^{2}\right) ; \mathrm{W}_{\mathrm{o}}=$ area below CMOD curve upto failure; $\mathrm{W}_{1}=$ work done by self-weight of specimen and loading jig; $\mathrm{A}_{\text {lig }}=$ Area of broken ligament; $\mathrm{m}_{1}=$ mass of specimen $(\mathrm{kg}) ; \mathrm{S}=$ loading span $(\mathrm{mm}) ; \mathrm{L}=$ total length of the specimen $(\mathrm{mm}) ; \mathrm{m}_{2}=$ mass of $\mathrm{jig}$ not attached to testing machine but placed on machine until rupture $(\mathrm{kg}) ; \mathrm{g}=$ gravitational acceleration $\left(9.807 \mathrm{~m} / \mathrm{s}^{2}\right)$; $\mathrm{CMOD}_{\mathrm{C}}=\mathrm{crack}$ mouth opening displacement at failure $(\mathrm{mm})$

\subsection{Acoustic Emission Monitoring}

During the fracture test on notched specimens, four narrow band (50 kHz to $300 \mathrm{kHz})$ and four wide band (100 kHz to $1 \mathrm{MHz}$ ) AE sensors supplied by Physical Acoustics Corp. (PAC), USA were used. As far as the literature review done by authors is concerned, this study uses 
types of sensors covering a wide spectrum of frequency is used in order to capture signals at

261 large range of frequency. Analysis of AE data reveals that the average frequency of hits varied

262 from $50 \mathrm{kHz}$ upto $350 \mathrm{kHz}$. These sensors were attached to the beams at the locations defined

263 by the coordinates given in Table 5. The test set-up along with the AE equipment is shown in

264 the Figure 2. A close-up of AE sensors and amplifier is shown in Figure 3. In addition, a

265 schematic of sensor placement is depicted in Figure 4. In this study, three dimensional

266 event/source location of damage is attempted. The preamplifier gain was set to $40 \mathrm{~dB}$. After

267 performing a pilot test, the threshold was set to $40 \mathrm{~dB}$ in order to nullify the effect of

268 electronic/environmental noise. Calibration of sensors was performed before each test to ensure

269 proper bonding of the AE sensors to the surface. The signals were recorded in an eight-channel

270 AE data acquisition (DAQ) card and the signals were recorded at a sampling rate of $5 \mathrm{MHz}$.

271 For the purpose of calibration, lead pencil break test were performed on different locations on

272 the surface of specimen. These calibration results showed the source location is within a range

273 of $5 \%$ error. Therefore, the source location results remained less effected from the impedance

274 difference between the foam, fibers and the concrete matrix.

275

276

TABLE 5. Co-ordinates of the AE sensors

\begin{tabular}{|c|c|c|c|}
\hline Sensor number & X-co-ordinate $(\mathrm{mm})$ & Y-coordinate $(\mathrm{mm})$ & Z-coordinate $(\mathrm{mm})$ \\
\hline 1. & 175 & 0 & 50 \\
\hline 2. & 175 & 0 & 150 \\
\hline 3. & 275 & 0 & 50 \\
\hline 4. & 275 & 150 & 150 \\
\hline 5. & 175 & 150 & 50 \\
\hline 6. & 175 & 150 & 150 \\
\hline 7. & 275 & 150 & 50 \\
\hline 8. & 275 & 150 & 150 \\
\hline
\end{tabular}

277 


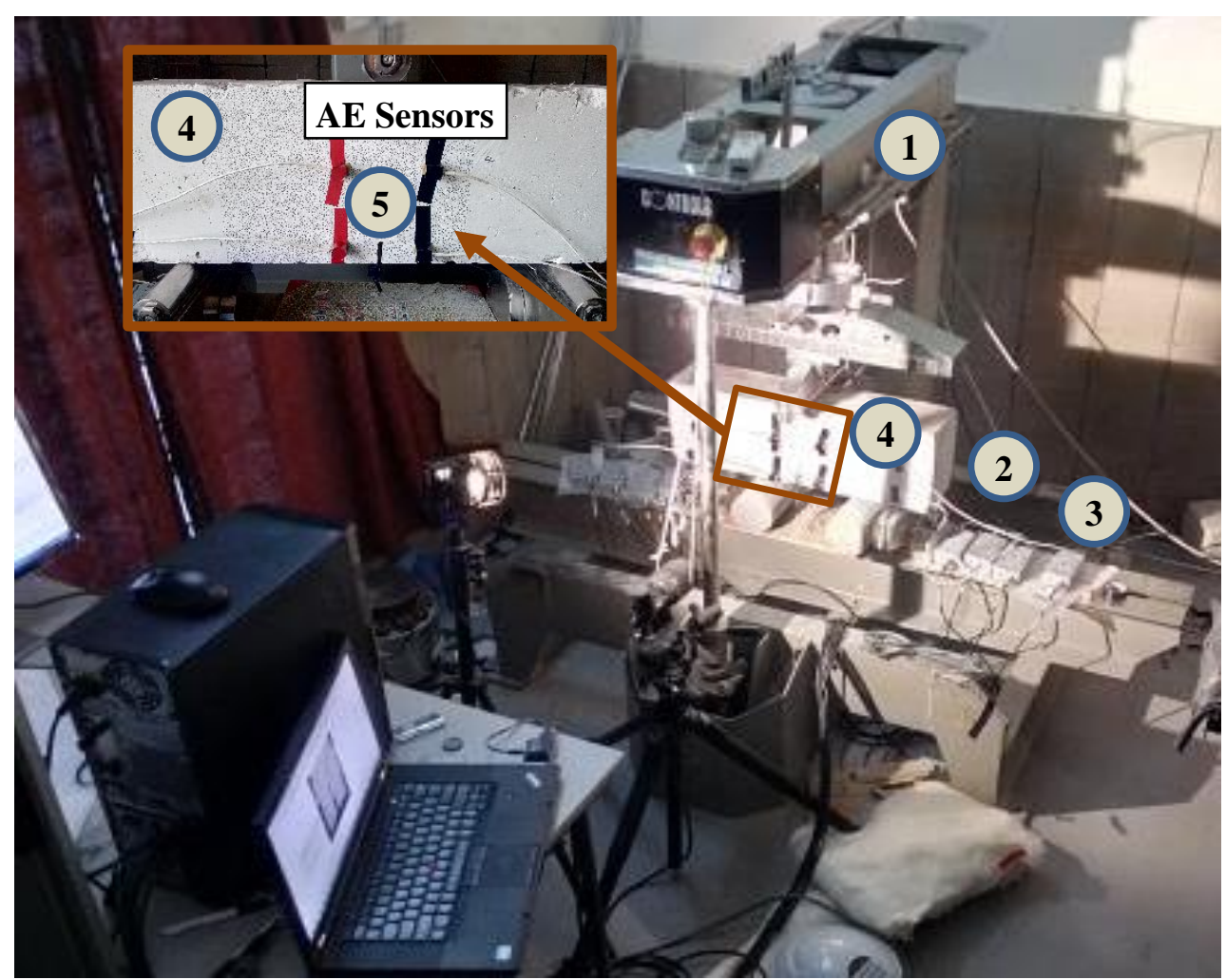

1. Controls Flexure Testing Machine 2. Notched FRCLC Specimen 3. Amplifier for AE Sensors 4. Positions of AE Sensors 5. Notch

Figure 2: Flexural Test Setup with Acoustic Emission Sensors

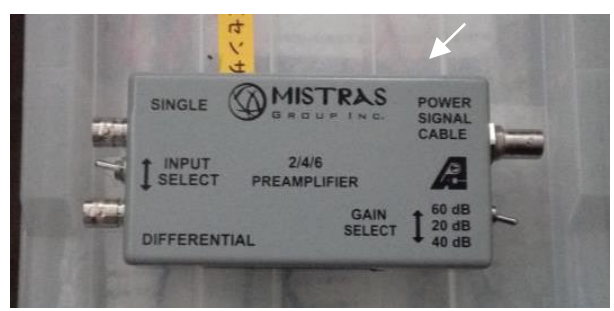

(a) Preamplifier

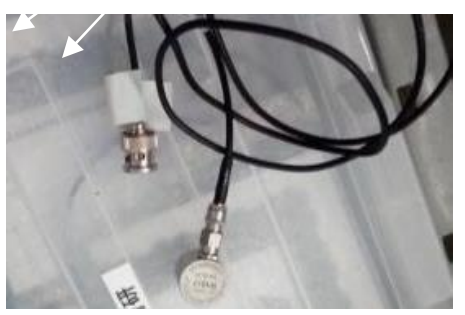

(b) AE sensor

Figure 3: Close up view of Acoustic emission sensing components

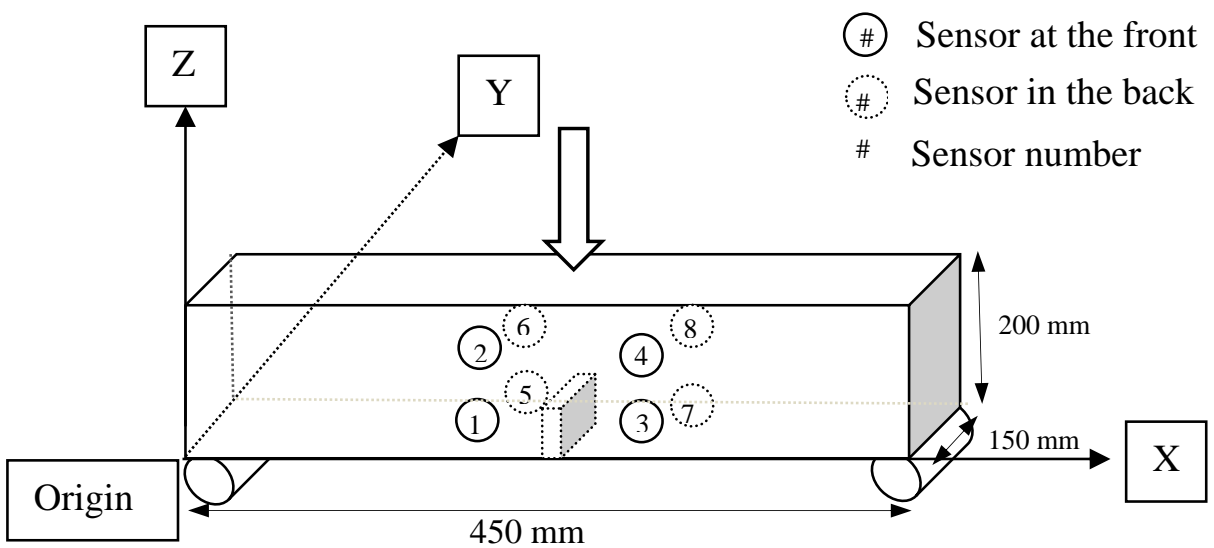

Figure 4: Schematic sketch for Acoustic Emission Sensor placement on notched FRCLC specimen 


\section{TEST RESULTS AND DISCUSSION}

\subsection{Flexural Fracture Test}

The fracture properties state the structural contribution of the fibres in the load resistance of CLC. Residual strengths obtained from fracture tests are typically used in the structural design. The post-cracking properties are important to understand the efficiency of fibers in improving the ductility of CLC. Figure 5 shows the load versus crack mouth opening displacement response of notched FRCLC beams for different fibe dosages. Figure $5 \mathrm{a}$ and $5 \mathrm{~b}$ shows the fracture behavior for CLC with macro and hybrid fibers, respectively. Upto the cracking of concrete matrix, the fiber reinforcement increases the cracking load of fiber reinforced CLC. After initiation of crack, the plain concrete exhibits decline in the load displacement response, whereas the fiber reinforced CLC performs better in terms of ductility and post-peak toughness. When macro fibers are elongated and pulled out from matrix, the energy would be consumed continuously in overcoming the interface strength between the fiber and the matrix resulting in significant improvement of the ductility of CLC. The post cracking load resistance is from fiber elongation followed by a combination of fiber pull-out and rupture. There is softening in the load response immediately after the peak load due to significant cracking and loss of stiffness.

In FRCLC specimens, there is an increase in the load carrying capacity with increasing crack opening (Figure 5a and 5b). The load recovery after the first cracking is initiated at a smaller value of crack opening displacement and a higher resistance is achieved during the load recovery with increase in the volume fraction of fibers. The increase in the residual load carrying capacity with increasing CMOD indicates that the macro synthetic fibers are efficient in providing crack closing stresses with increasing CMOD. The test results are summarized in Table 6. First cracking and peak loads increased with increasing fiber dosage. Moreover, the difference between cracking and peak load increased in beams with macro fiber dosage with increase in fiber dosage. However, the first cracking load increase in hybrid fiber reinforced 
specimens and the difference between cracking and peak load reduced with increase in fiber dosage.

Hybrid combination of macro and micro fiber as reinforcing components could increase effectively the toughness and ability of CLC in resisting fracture. This is reflected in the load vs CMOD curves (Figure 5c) that synergistic reinforcing effect between macro and micro fibers were good. This is due to the fact that hybrid fibers with different lengths and diameter played their corresponding roles at different scales. In micro-crack phase (CMOD $<0.1 \mathrm{~mm})$, micro fiber can restrain crack development and restrict the propagation of micro-crack in matrix. In macro-crack phase (CMOD $>0.1 \mathrm{~mm})$, micro fibers appeared to be less effective in controlling the CLC matrix crack opening due to complete pull-out of micro fibers [41]. However, due to relative larger interface strength between macro fiber and CLC matrix, the efficiency of macro fibers in arresting the structural/macro cracks would be higher. When macro fibers are elongated and pulled out from the CLC matrix, the energy would be consumed continuously, and the ductility of CLC fiber reinforced composite improves significantly. When the total fiber volume fractions are kept the same, the reinforcement effects of hybrid combination of macro and micro fibers is much better than the CLC specimens with only macro fibers. For example, the addition of $0.02 \%$ of micro fibers with $0.4 \%$ macro fiber resulted in improvement of $34 \%$ in fracture load. However, no difference in peak load was observed between hybrid and macro fiber reinforced CLC (Table 6, Figure 5c). 


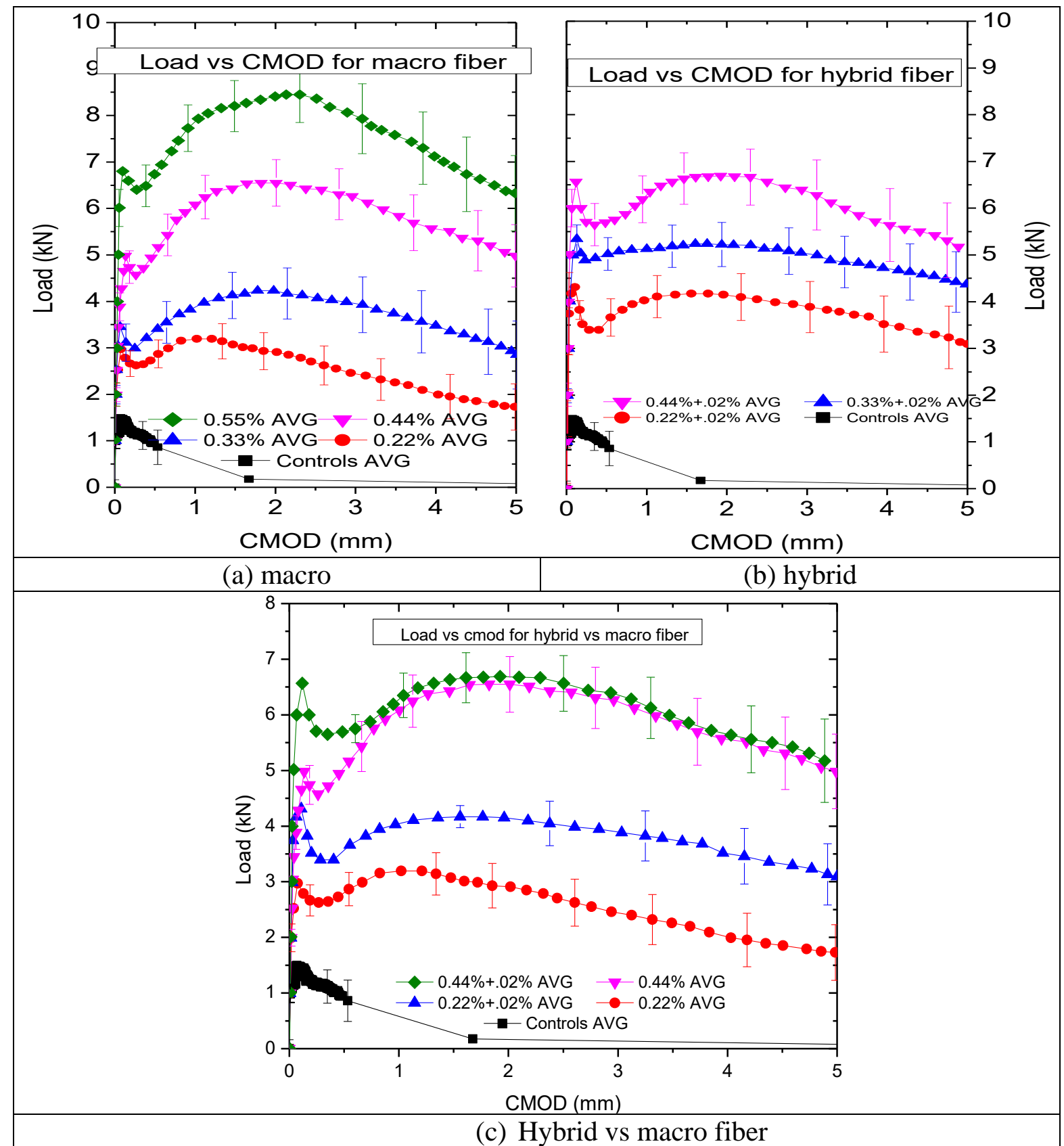

Figure 5: Load vs Avg. CMOD opening of FRCLC under flexure

\subsection{Cracking Modes}

Change in crack patterns with increase in fiber dosage at failure indicates the change in

failure mode. Figure 6 shows the visual crack opening modes of the tested specimens. Figure 6(a) and 6(b) shows the front and back view of visual crack opening modes in plain CLC.

Control specimen showed a brittle response in flexure, wherein the crack path was observed to be perpendicular to the bending axis of the specimen. This may be a result of very little resistance offered by matrix in post-crack formation stage. On the other hand, crack growth in 
FRCLC specimen was observed to be meandering along the plane of notch. This can be attributed to the low strength of the matrix and high strength of fiber, which makes the crack path to search for the path of least resistance inside the matrix where fibers are randomly distributed (Figure 6c).

\subsection{Acoustic hits and Energy Dissipation}

(a) front view of plain CLC

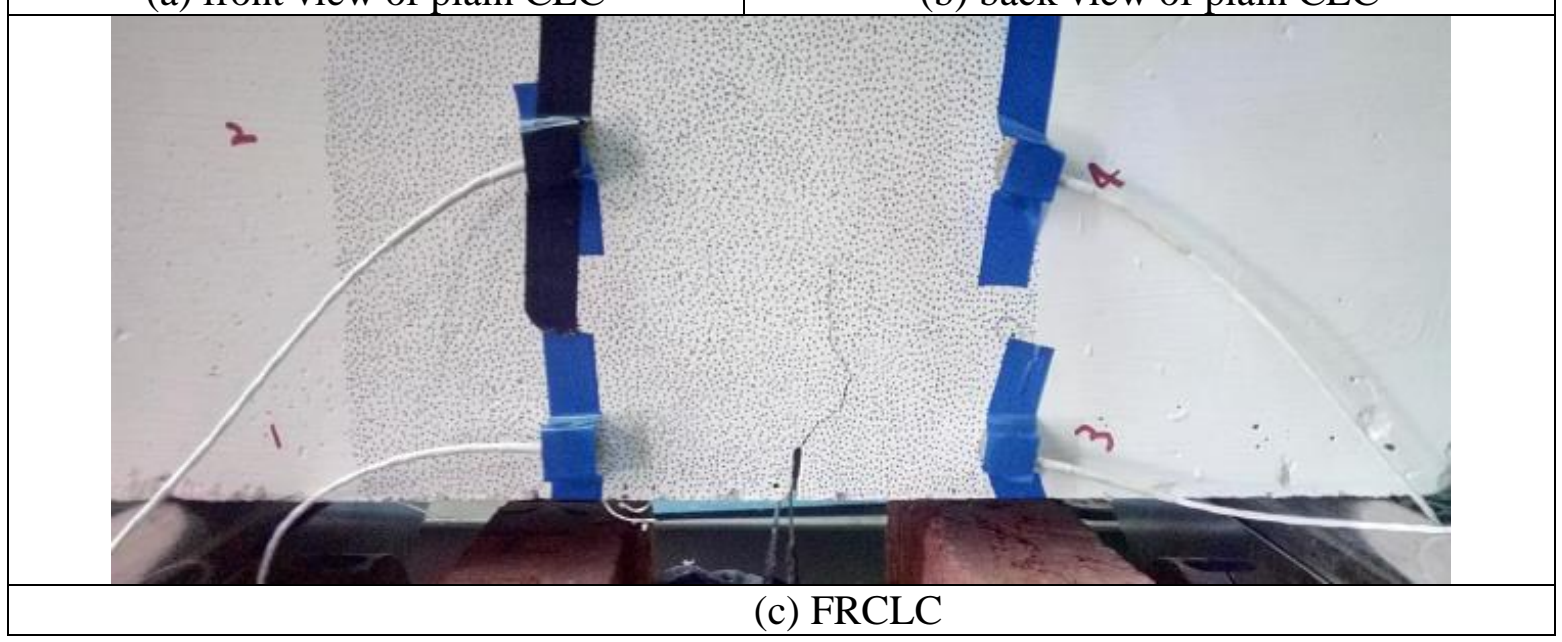

Figure 6: Cracking of CLC under flexure

In order to clarify the fracture resistance, acoustic emission (AE) monitoring is employed during fracture tests. Acoustic energy emission is the phenomenon where the strain energy stored inside the specimen gets transmitted through the material, when it is subjected to stress generated by load application or thermal gradient. This energy is transmitted in the form of elastic waves and gets picked up by $\mathrm{AE}$ sensors. The first part of $\mathrm{AE}$ analysis deals with the plotting of cumulative AE energy and AE counts with respect to load vs CMOD. This results 
in a quantitative estimate of crack opening and load when a certain value of AE energy and counts are obtained. Failure in CLC can be due to matrix cracking and interface failure between the voids and CLC matrix. The possibility of delaying the crack growth due to fibre action increases with increasing fibre volume content. Consequently, the material toughness is enhanced. In fiber reinforced CLC, the fibre pull-out also contributes to the final failure. The distinct fracture mechanisms emit AE signals with different characteristics. Therefore, many AE parameters of the recorded waves such as rise time, count, amplitude and duration are studied in order to understand the distinct failure mechanisms in CLC.

The number of counts in a particular hit gives the idea of relative difference within the domain of hits. The authors have observed a smooth trend when cumulative number of counts were plotted against the CMOD. The plot of AE energy vs CMOD showed a couple of hikes in the curve due to the fiber breaking instances. Hence to ascertain the crack width at a particular instant of AE counts number of counts are considered in a cumulative approach.AE activity is very important as high rate of $\mathrm{AE}$ recording is linked to high rate of crack propagation. Similarly, very little or limited AE activity implies lesser crack propagation. Thus, the total number of $\mathrm{AE}$ hits recorded with respect to the measurement time is the fundamental parameter for understanding the role of fibers in crack arresting. Figure 7a \& 8a shows the variation of cumulative acoustic energy against the applied load with respect to increasing value of CMOD for macro fibers and hybrid fibers, respectively. For both cases, three different fiber dosages such as $0.33 \%, 0.44 \%$ and $0.55 \%$ are considered for evaluation. Hybrid fiber dosage included a constant dosage of $0.02 \%$ micro fibers in addition to macro fibers.

The recorded energy at both sensors is combined for the calculation of cumulative energy. The combined energy is a superposition of the energy received from both types of sensors. The 
trend of energy recorded vs CMOD remains the same even if only one type of sensors are used. However, the numbers may vary accordingly. Energy and counts are plotted using data from all the sensors rather than just the source location data. The source location points are generated for hits where at least three sensor data coincides at a point. This may not be recorded for all the hits generated. Energy and counts from the source location data alone are lesser compared to the overall data captured which can under predict the actual AE energy and the generated counts. Therefore, all the data recorded by the eight sensors are used to investigate the $\mathrm{AE}$ energy and the cumulative number of counts. Cumulative AE counts with load vs CMOD are compared in Figure $7 \mathrm{~b}$ and $8 \mathrm{~b}$ for macro and hybrid fibers, respectively. Number of AE events increased significantly up to the peak load and the rate of increase in AE events reduced after peak load in both the beams with macro and hybrid fibers. Before cracking, lesser number of AE hits and AE energy was recorded. After the load drop, the increase in AE rate decreases but it does not cease completely. Concerning the mechanical behavior, soon-after the first macro-crack develops, load typically drops by several $\mathrm{kN}$. The AE energy is found to increase with increase in fiber dosage (Figure 7a \& 8a). Using this information, the damage behavior of structural element can be quantified for the average crack opening recorded between the $\mathrm{AE}$ sensor configuration.

\section{Figure 9a and 9b shows the plot of CMOD against the number of cumulative AE counts for} macro and hybrid fibers, respectively. The increase in number of AE hits and AE energy in the post-cracking region can be attributed to the fiber pull-out and breaking of fibers. Normalized AE energy vs fracture energy of FRCLC under flexure is plotted in Figure 10. It clearly shows that the addition of synthetic fibers significantly improved the fracture behavior of CLC. Addition of even a small amount of micro fibers in hybrid fiber combination significantly increased the fracture energy of CLC when compared to only macro fiber addition. For 
406 increased by a factor of three when compared to control beam.

407 


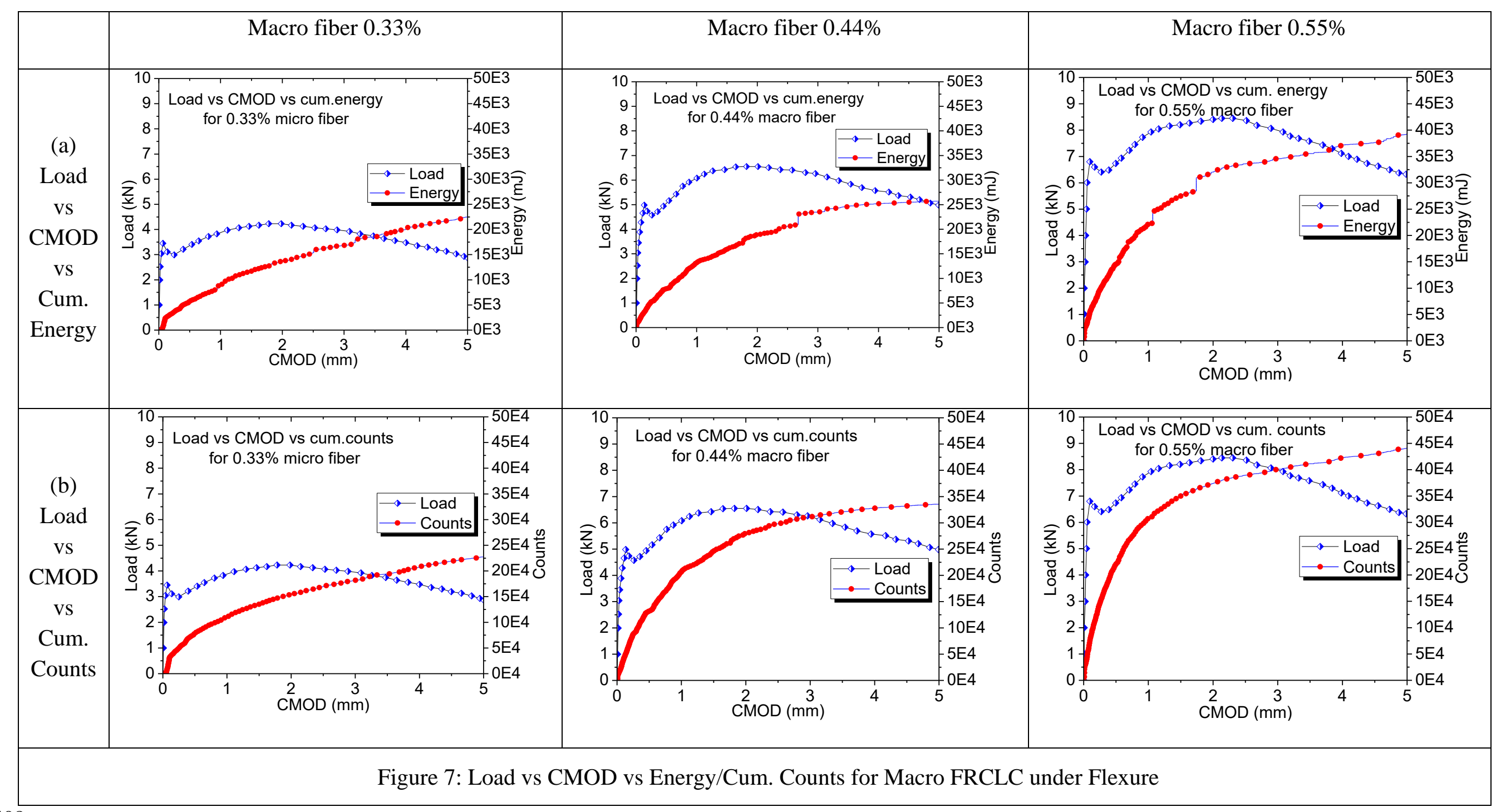




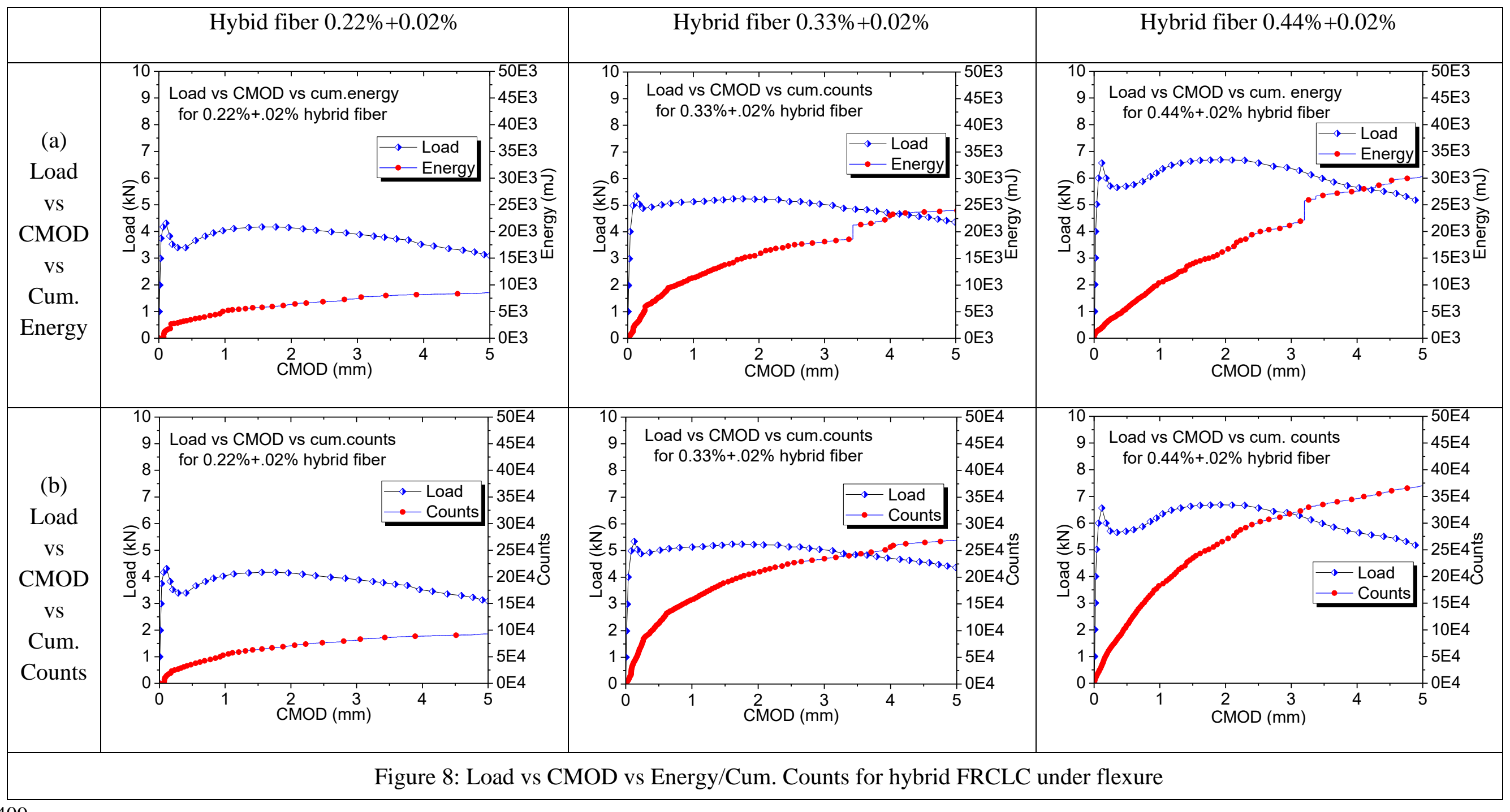




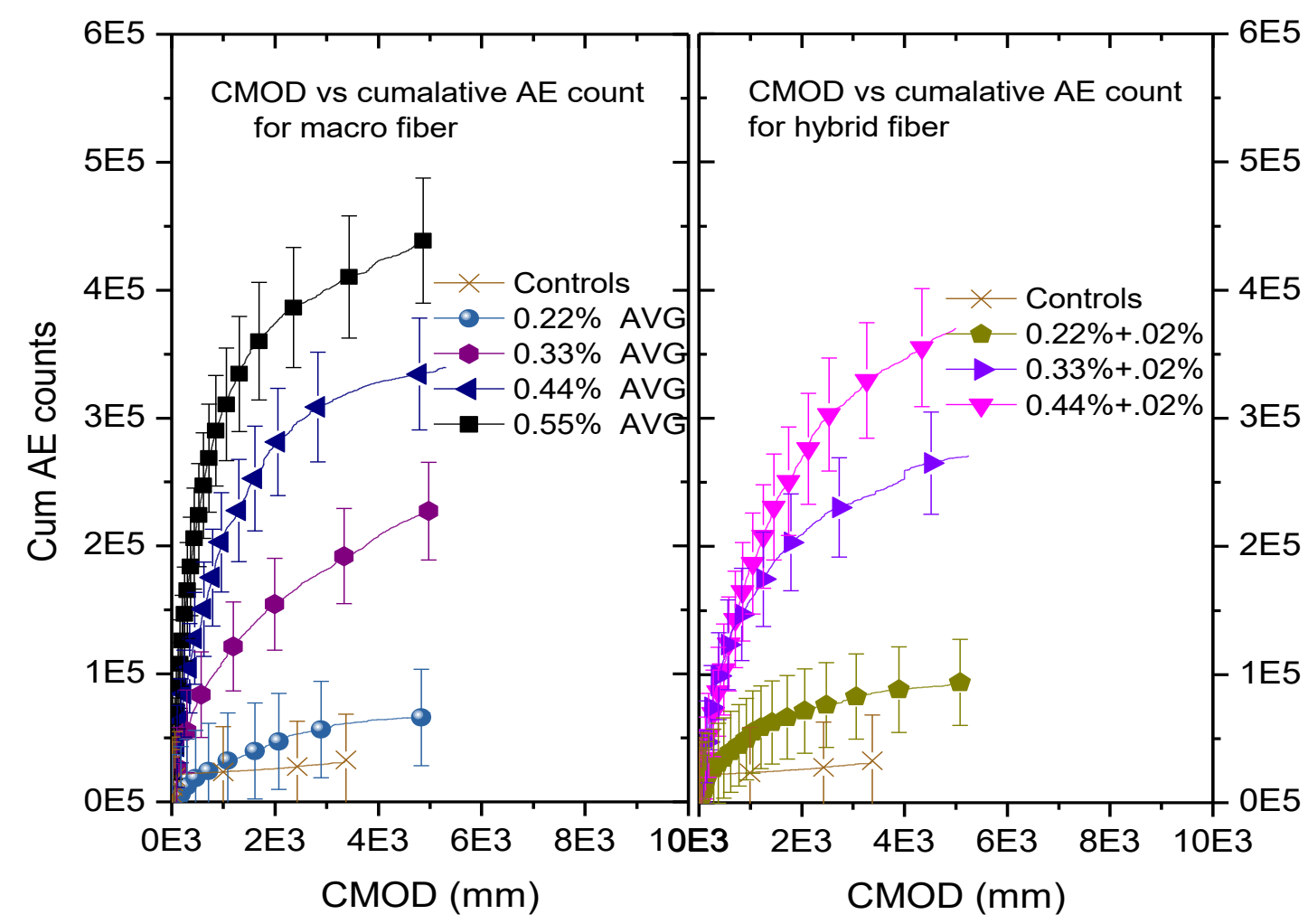

Figure 9: Cumulative AE count vs Avg. CMOD opening of FRCLC under flexure 

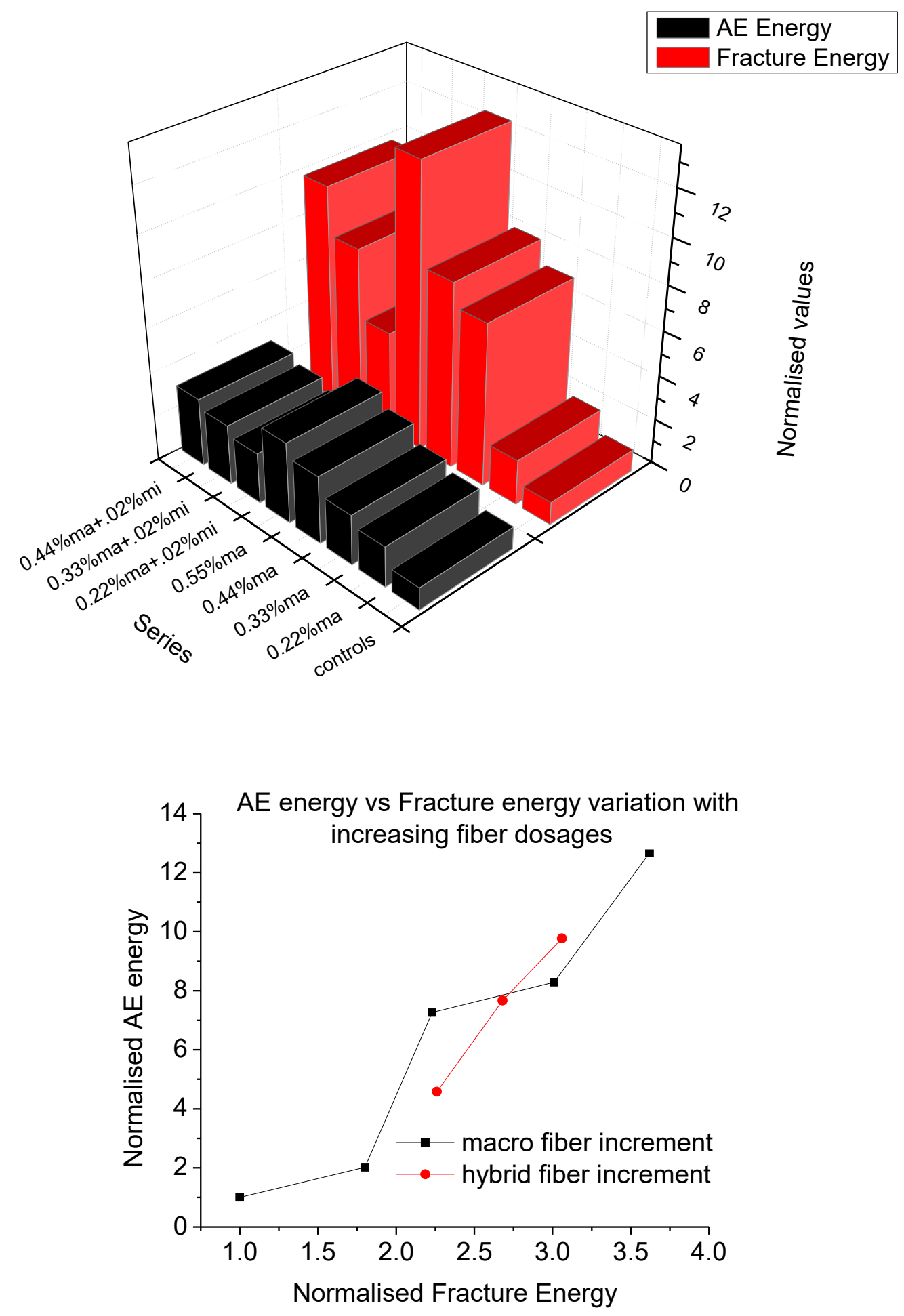

5. IDENTIFICATION OF 3D-CRACK LOCATION AND DIFFERENTIATION OF CRACKING MODE

Figure 10: Normalized AE energy vs fracture energy of FRCLC under flexure

Identification of fracture process zone (FPZ) is of prime importance in structural health monitoring and retrofitting of structural elements. AE source location can be potentially applied 
to identify FPZ. Furthermore, the mode of failure has to be properly distinguished in order to understand the global failure mechanism in a structural element. The dimension of specimen i.e, $450 \mathrm{~mm}$ length $150 \mathrm{~mm}$ width and $200 \mathrm{~mm}$ height during the test were simulated for 3D crack location and differentiation of cracking modes using a MATLAB program. The second part of AE analysis deals with the detection of source location. Every sensor generates a distance from which it is picking up a particular signal, which may be visualized in the form of a hollow sphere. At the same time, if two or more signals are picking up the same signal, the overlap of these three signals results in the hit source location which can be visualized as intersection point between three hollow spheres. For the located signal, the corresponding RA value and Average Frequency values are calculated and their ratio is used to differentiate the localized mode of failure. The initiation of AE event and its mode of failure at a local level may correspond to matrix cracking or fiber pull-out, which then can be correlated to mode I or mode II, respectively. The differentiation of different $\mathrm{AE}$ events was done based on the parameter based method. Definitions of different terms used in AE analysis is defined in Figure 11a. RA value is defined as the ratio of the rise time to the waveform amplitude. Average frequency is defined as the number of threshold crossings (counts) divided by the duration of the signal (Figure 11a). It is expressed in kHz. Analysis of AE results based on parameter based method (Figure 11b) helps to differentiate the tensile and shear mode. The parameter based method involves calculation of two parameters viz,. RA value and Average Frequency (AE ring-down counts/Duration time) and plotting them on $\mathrm{X}$ and $\mathrm{Y}$ axis respectively as shown in Figure 11a. The events are then classified based on the region which they lie as shown in the Figure $11 b$. 


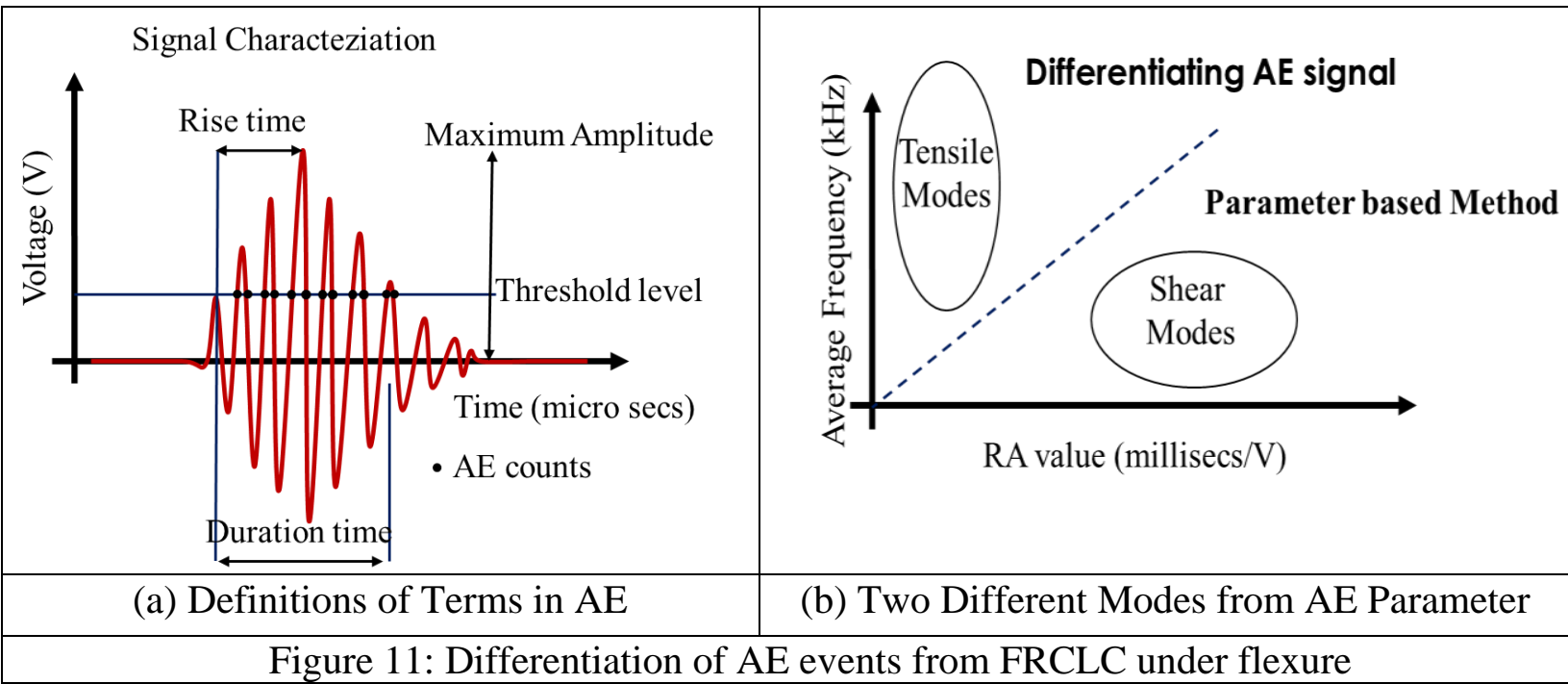

In general, the tensile cracks in mode I produces AE signals with high frequency. However, the shear type of crack (mode II) produces AE signals of lower frequency. Initially, tensile matrix cracking (mode 1) initiated on the tension side (bottom surface) due to tensile stresses. At higher loads, with extension of crack to the compression side, occurrence of fiber friction and pull-out events (shear, mode II) begins. In the final stages close to failure, the fibre pullout events dominate the process when the two parts of the CLC specimen separates completely. Previous studies on crack classification in concrete based on AE has shown that the value of slope of line, which differentiates the modes of failure, can be kept as 200 for a good correlation with SiGMa procedure. For the purpose of this study of FRCLC, the slope value of 200 gives a good correlation with SiGMa procedure $[9,10,14]$.

Normalized values of AE and fracture energy shows a trend with AE energy values close to almost three times that of fracture energy values for higher fiber dosages. Summary of results including cracking load, peak load, fracture energy and AE energy are summarized in Table 6. This shows that the measurement of AE energy has a direct correlation with the fracture energy and toughness of the CLC. Moreover, addition of fibers increases the cumulative AE energy. 
462 AE energy for hybrid fiber reinforced CLC was higher than that of CLC beams with only macro 463 fibers. Figure 12 shows the AE crack source location in three dimensional space for fiber reinforced CLC for different fiber dosages. Figure 12a shows the schematic of specimen which is taken as a reference in subsequent figures for source location. Figure $12 \mathrm{~b}$ shows the crack source location for controls specimen. It is clearly observed that the dominant event in AE source location is mode I. Figure $12 \mathrm{c}$ and $12 \mathrm{~d}$ shows the crack source location for macro fiber reinforced CLC with $0.55 \%$ and $0.44 \%$ respectively. Similarly, the Figure $12 \mathrm{e}$ and $12 \mathrm{f}$ show the crack source location for hybrid fiber reinforced CLC with $0.33 \%$ and $0.44 \%$ of macro fiber dosage with a constant micro fiber dosage of $0.02 \%$. The corresponding distribution of events and their failure modes were plotted on histograms along the length and height of the specimen and placed on the top and right side, respectively. The events that were recorded during the testing were differentiated as two modes of failure viz., shear and tensile mode. Plain CLC failure failed in tensile mode of failure. FRCLC showed a predominant shear mode of failure at high fiber dosages (Figure 12). Failure of FRCLC can be observed from the histograms of number of events corresponding to shear and tensile modes that are plotted alongside the AE hits. It can also be identified from the histograms that there is a normal distribution trend of AE events followed along the length of the specimen. The relative ratio of contribution from shear modes is shown to increase along the length as well as along the height directions. The tensile modes increase towards the downward region of the notch, whereas the shear modes increase from top, reaches a maximum value and then decreases towards the downward region. It is also observed that the fiber reinforcement tends to shift the mode of failure from tensile to shear mode. 
mode of fracture is dominant for plain CLC. The mode of fracture is changing to shear with increase in fiber dosage. This demonstrates the reinforcing effect of the fibres against the weak tensile behavior of CLC. The study of AE indices implies that the mode of fracture changes during the experiment from tensile (initial stage) to shear (final fracture). This is macroscopically shown by the crack splitting and deflection from parallel to perpendicular direction relatively to the loading axis. In addition, the fracture process zone increases simultaneously with increasing fiber content. Though limited specimens were tested, the results are promising and provide confidence that acoustic emission technique can be used for the identification of the different fracture modes. Source location and identification of cracking behavior provides valuable insight for choosing optimum fiber dosage at a given stress state.

Moreover, crack classification using suitable AE descriptors shown in in Figure 11b can assist in the evaluation of the severity of the condition as the shear mode typically follows the tensile mode in fiber reinforced CLC.

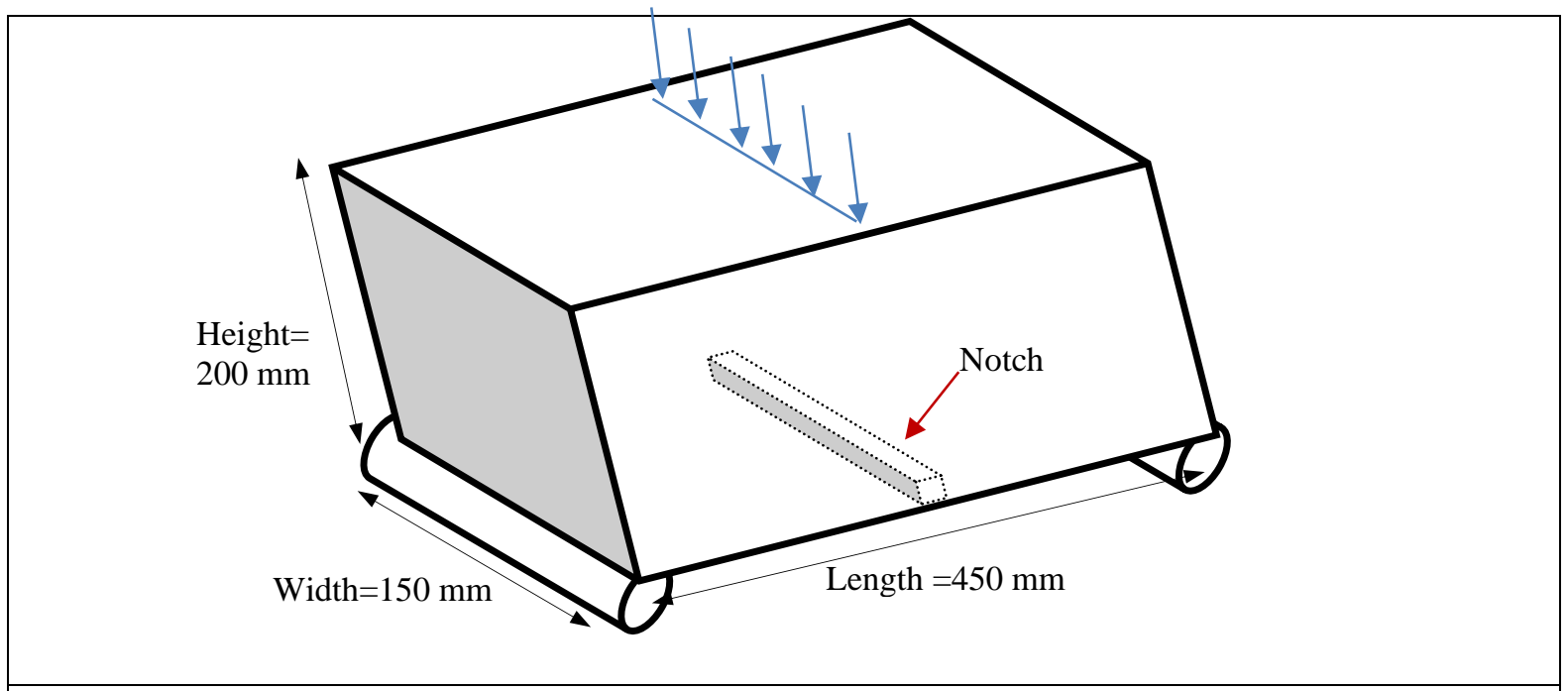

(a) Schematic of specimen 


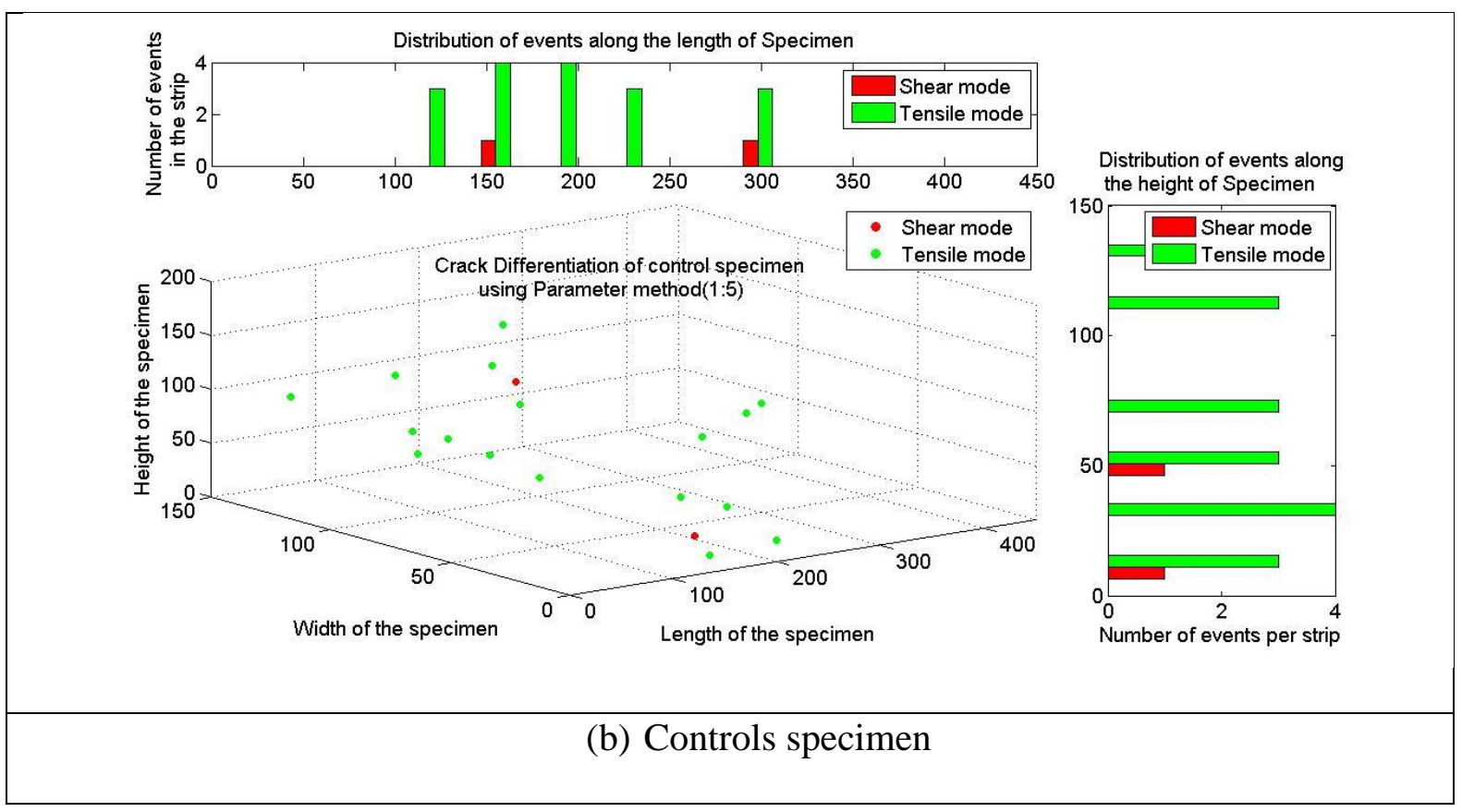



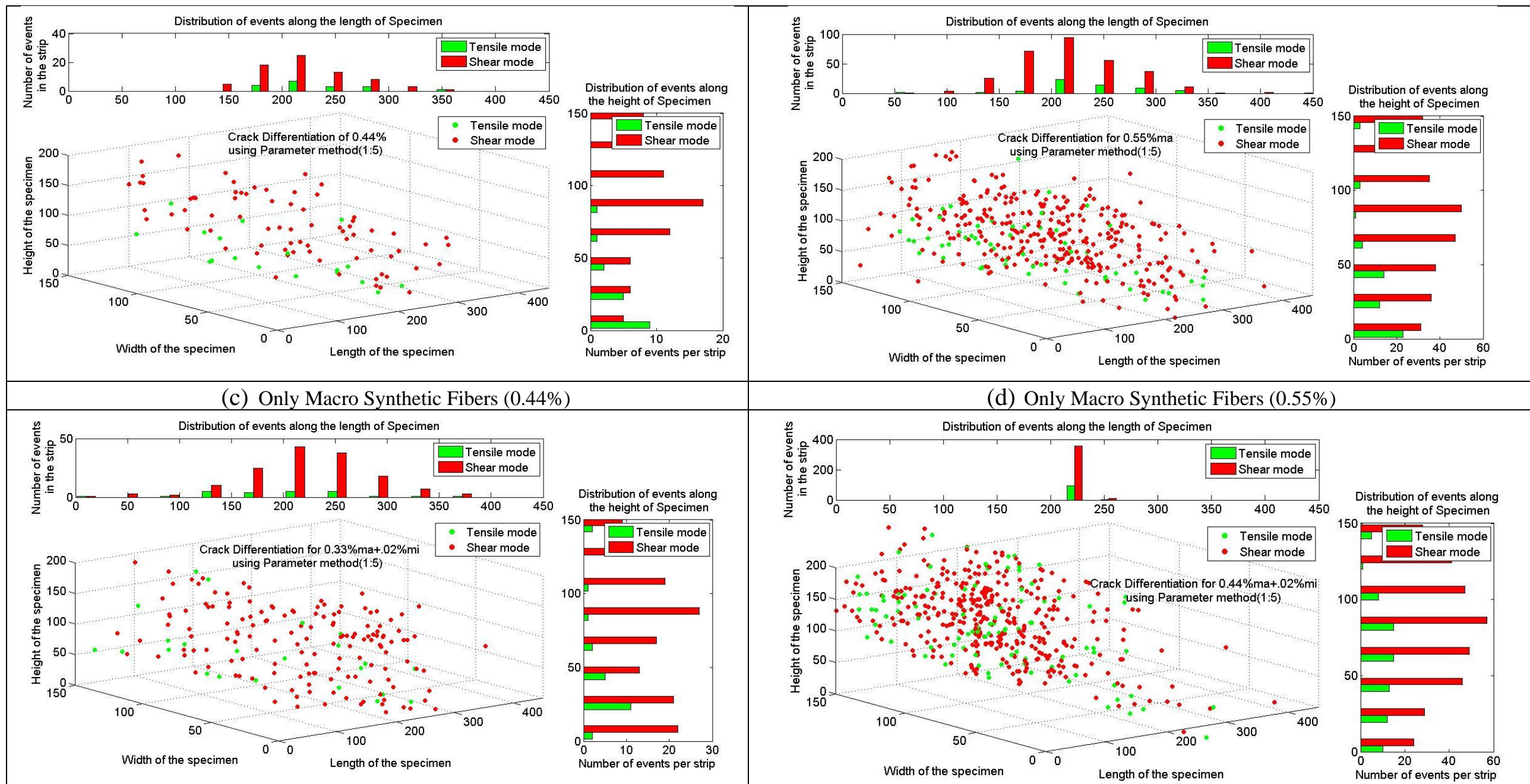

hes

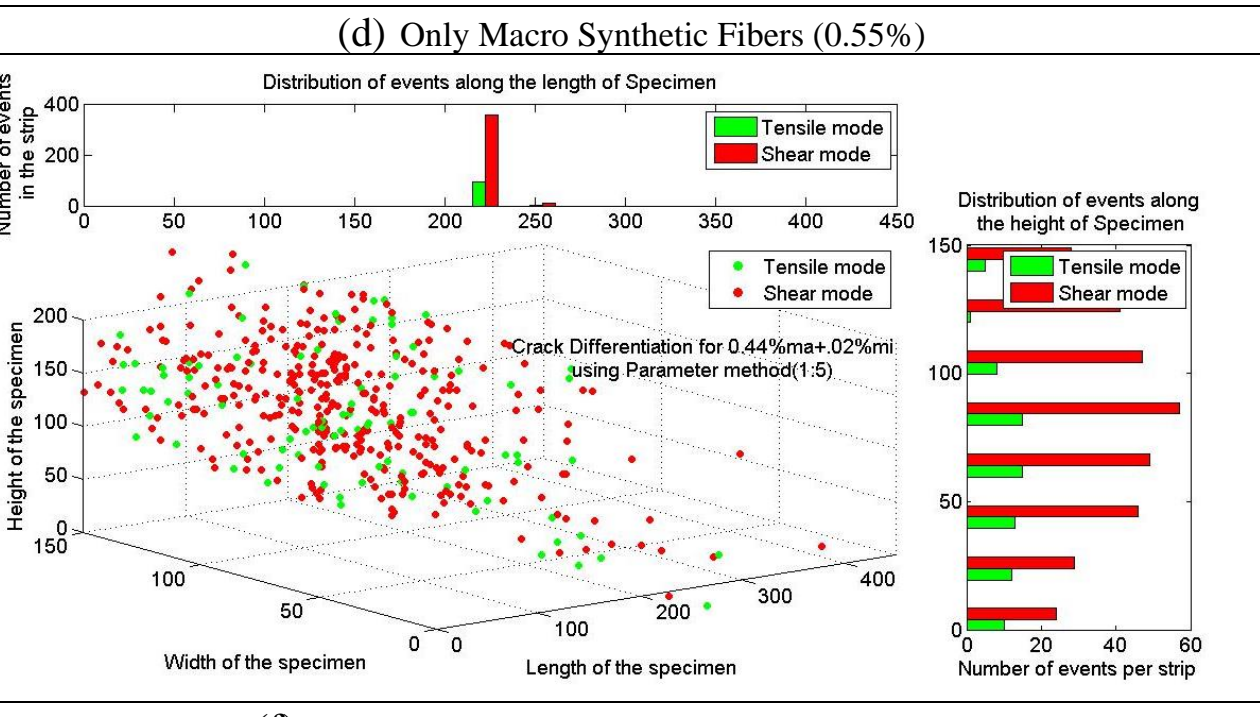

(e) Hybrid Synthetic Fibers $(0.33 \% \mathrm{ma}+0.02 \% \mathrm{Mi})$

(f) Hybrid Synthetic Fibers $(0.44 \% \mathrm{ma}+0.02 \% \mathrm{Mi})$ 
TABLE 6. Fracture parameters and AE energy values.

\begin{tabular}{|c|c|c|c|c|c|c|c|c|c|c|c|c|}
\hline \multirow{2}{*}{ Series } & \multirow{2}{*}{ Specimen } & \multicolumn{3}{|c|}{ Peak Load (kN) } & \multirow{2}{*}{$\begin{array}{l}\text { Mean } \\
\text { Peak } \\
\text { Load } \\
(\mathbf{k N})\end{array}$} & \multirow{2}{*}{$\begin{array}{c}\text { Standard } \\
\text { Deviation } \\
(\mathbf{k N})\end{array}$} & \multirow{2}{*}{$\begin{array}{c}\text { Fracture } \\
\text { Load } \\
(\mathbf{k N})\end{array}$} & \multirow{2}{*}{$\begin{array}{c}\mathbf{W}_{\mathbf{o}} \\
\left(\mathbf{N} / \mathbf{m m}^{2}\right)\end{array}$} & \multirow{2}{*}{$\begin{array}{c}\mathbf{G}_{\mathbf{F}} \\
\left(\mathbf{N} / \mathbf{m m}^{2}\right)\end{array}$} & \multirow{2}{*}{$\underset{\mathbf{G}_{F}}{\text { Normalized }}$} & \multirow{2}{*}{$\begin{array}{c}\text { Acoustic } \\
\text { Emission } \\
\text { Energy } \\
(\mathbf{J})\end{array}$} & \multirow{2}{*}{$\begin{array}{c}\text { Normalized } \\
\text { Acoustic } \\
\text { Emission } \\
\text { Energy }\end{array}$} \\
\hline & & 1 & 2 & 3 & & & & & & & & \\
\hline $\mathbf{I}$ & Control & 1.75 & 1.22 & 1.48 & 1.49 & 0.37 & 1.49 & 1.71 & 605.7 & 1.00 & 3.1 & 1.00 \\
\hline \multirow{3}{*}{$\begin{array}{c}\text { II } \\
\text { (only } \\
\text { Macro) }\end{array}$} & ma-0.2-mi-0.0 & 3.26 & 3.46 & 2.83 & 3.19 & 0.32 & 2.96 & 12.65 & 1091.9 & 1.80 & 7.9 & 2.02 \\
\hline & ma-0.3-mi-0.0 & 3.48 & 4.26 & 4.94 & 4.23 & 0.73 & 3.44 & 18.49 & 1351.5 & 2.23 & 22.5 & 7.26 \\
\hline & ma-0.5-mi-0.0 & 9.35 & 8.20 & 7.79 & 8.45 & 0.81 & 6.80 & 37.40 & 2191.9 & 3.62 & 39.3 & 12.67 \\
\hline \multirow{3}{*}{ III (hybrid) } & ma-0.2-mi-0.02 & 4.98 & 3.92 & 4.02 & 4.31 & 0.59 & 4.31 & 18.92 & 1370.7 & 2.26 & 14.2 & 4.58 \\
\hline & ma-0.3-mi-0.02 & 5.01 & 4.89 & 6.11 & 5.34 & 0.67 & 5.34 & 24.61 & 1623.5 & 2.68 & 23.8 & 7.67 \\
\hline & ma-0.4-mi-0.02 & 7.01 & 5.69 & 6.97 & 6.56 & 0.75 & 6.69 & 29.73 & 1851.1 & 3.06 & 30.3 & 9.77 \\
\hline
\end{tabular}

Note:

- ma- macro fiber; mi- micro fiber; $0.2,0.3,0.4,0.5$ - volume fraction of fibers in $\%$.

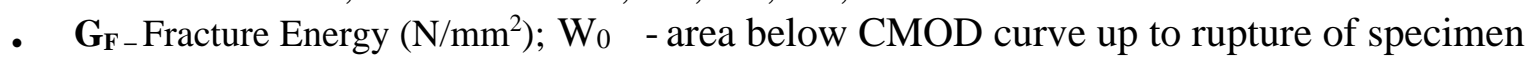




\section{SUMMARY AND CONCLUSIONS}

512 Notched fiber reinforced CLC beams were tested under flexure to understand the fracture and

513 acoustic emission behavior. Fracture tests for FRCLC has been performed and variation of 514 CMOD with respect to different fiber dosages was studied. Various AE parameters such as 515 energy and cumulative counts were plotted against the applied load and CMOD. Cumulative 516 AE count is established against the CMOD in an attempt to quantify the crack opening using 517 the AE technique. In addition to this, 3D source location of cracks and cracking modes was 518 carried out. Based on the limited results presented in this study, the following major 519 conclusions can be drawn:

520 - Addition of synthetic fibers significantly improves the fracture behavior of CLC. 521 Addition of even a small amount of micro fibers in hybrid fibers, significantly improves

Density is a very important parameter that affects the mechanical properties of CLC. Future work should focus on understanding the AE monitoring of CLC elements by including 
various parameters such as different types and volume fractions of fibers and the effect of density on the fracture behavior of fiber reinforced CLC.

\section{ACKNOWLEDGEMENTS}

This work has been carried out as a joint collaboration between Indian Institute of Technology Hyderabad, India and Ritsumeikan University, Japan. The authors gratefully acknowledge the financial support lend by Department of Science and Technology, India through Grant No: SR/S2/RJN-30/2012, YSS/2015/000677. Brugg Contec AG and Grenix Infrastructure Ltd donated the fibers for this research. The authors duly acknowledge their support.

\section{REFERENCES}

[1] B. Zhang and C. S. Poon, "Use of Furnace Bottom Ash for producing lightweight aggregate concrete with thermal insulation properties," J. Clean. Prod., vol. 99, pp. 94100, 2015.

[2] K. Ramamurthy, E. K. K. Nambiar, and G. I. S. Ranjani, "Cement \& Concrete Composites A classification of studies on properties of foam concrete," Cem. Concr. Compos., vol. 31, no. 6, pp. 388-396, 2009.

[3] M. R. Jones and A. Mccarthy, "Preliminary views on the potential of foamed concrete as a structural material," no. 1, pp. 21-31, 2005.

[4] Z. Zhang, J. L. Provis, A. Reid, and H. Wang, "Geopolymer foam concrete: An emerging material for sustainable construction," Constr. Build. Mater., vol. 56, pp. 113-127, 2014.

[5] R. F. Zollo and C. D. Hays, "Engineering material properties of a fiber reinforced cellular concrete," ACI Mater. J., vol. 95, no. 5, pp. 631-635, 1998.

[6] M. A. Rasheed and S. S. Prakash, "Effect of Synthetic Fiber Reinforcement on Compression and Tension Behavior of Cellular Lightweight Concrete," in 9th RILEM International Symposium on Fiber Reinforced Concrete- BEFIB 2016, Vancouver, Canada, no. 9, pp. 632-641.

[7] M. A. Rasheed and S. S. Prakash, "Experimental study on compression behavior of fiber reinforced cellular concrete stack bonded masonry prisms," ACI Mater. J., 2018.

[8] M. A. Rasheed and S. S. Prakash, "Mechanical behavior of sustainable hybrid-synthetic fiber reinforced cellular light weight concrete for structural applications of masonry," Constr. Build. Mater., vol. 98, pp. 631-640, 2015.

[9] S. Jain, S. S. Prakash, and K. V. L. Subramaniam, "Monitoring of Concrete Cylinders With and Without Steel Fibers Under Compression Using Piezo-Ceramic Smart Aggregates," J. Nondestruct. Eval., pp. 1-7, 2016.

[10] M. A. Rasheed and S. S. Prakash, "Behavior of Hybrid-Synthetic Fiber Reinforced 
Cellular Lightweight Concrete under Uni-axial Tension - Experimental and Analytical Studies," Constr. Build. Mater., no. 29 (Accepted), 2017.

[11] M. A. Rasheed and S. S. Prakash, "Flexural Behavior of Synthetic Fiber Reinforced Cellular Light Weight Concrete," in 2nd R.N.Raikar International Conference and Banthia-Basheer International Symposium on Advances in Science and Technology of Concrete, Mumbai, India, 2015, pp. 1-7.

[12] M. A. Rasheed and S. S. Prakash, "Compression Behavior of Synthetic Fiber Reinforced Cellular Concrete Masonry Prisms," in 2nd R.N.Raikar International Conference and Banthia-Basheer International Symposium on Advances in Science and Technology of Concrete, Mumbai, India, 2015, no. 2, pp. 1-5.

[13] J. Huang, Q. Su, W. Zhao, T. Li, and X. Zhang, "Experimental study on use of lightweight foam concrete as subgrade bed filler of ballastless track," Constr. Build. Mater., vol. 149, pp. 911-920, 2017.

[14] M. Koz, M. Kadela, and A. Kukie, "Fracture energy of foamed concrete based on threepoint bending test on notched beams," Procedia Eng., vol. 108, pp. 349-354, 2015.

[15] B. Trunk, G. Schober, A. K. Helbling, and F. H. Wittmann, "Fracture mechanics parameters of autoclaved aerated concrete," Cem. Concr. Res., vol. 29, pp. 855-859, 1999.

[16] K. Ohno, K. Uji, A. Ueno, and M. Ohtsu, "Fracture process zone in notched concrete beam under three-point bending by acoustic emission," Constr. Build. Mater., 2014.

[17] M. Ohtsu and H. Watanabe, "Quantitative damage estimation of concrete by acoustic emission," Constr. Build. Mater., vol. 15, pp. 217-224, 2001.

[18] J. Berthelot, M. Ben Souda, and J. L. Robert, "Identification of Signals in the Context of Acoustic Emission in Concrete," J. Nondestruct. Eval., vol. 13, no. 2, pp. 63-73, 1994.

[19] M. G. R. Sause and S. Richler, "Finite Element Modelling of Cracks as Acoustic Emission Sources," J. Nondestruct. Eval., vol. 34, no. 4, pp. 1-13, 2015.

[20] E. N. Landis and S. P. Shah, "Recovery of Microcrack Parameters in Mortar Using Quantitative Acoustic Emission," J. Nondestruct. Eval., vol. 12, no. 4, pp. 219-232, 1993.

[21] D. Soulioti, N. M. Barkoula, A. Paipetis, T. E. Matikas, T. Shiotani, and D. G. Aggelis, "Acoustic emission behavior of steel fibre reinforced concrete under bending," Constr. Build. Mater., vol. 23, no. 12, pp. 3532-3536, 2009.

[22] N. Nor, A. Ibrahim, N. Muhamad, and H. Mohd, "Acoustic emission signal for fatigue crack classification on reinforced concrete beam," Constr. Build. Mater., vol. 49, pp. 583-590, 2013.

[23] S. Hu, J. Lu, and F. Xiao, "Evaluation of concrete fracture procedure based on acoustic emission parameters," Constr. Build. Mater., vol. 47, pp. 1249-1256, 2013.

[24] Y. Kawasaki, T. Kobarai, and M. Ohtsu, "Kinematics of Corrosion Damage Monitored by Acoustic Emission Techniques and Based on a Phenomenological Model Kinematics of Corrosion Damage Monitored by Acoustic Emission Techniques and Based on a Phenomenological Model," J. Adv. Concr. Technol., vol. 10, pp. 160-169, 2012.

[25] Y. Kawasaki, S. Wasada, T. Okamoto, and K. Izuno, "Evaluation for RC specimen damaged from rebar corrosion by acoustic emission technique," Constr. Build. Mater., vol. 67, pp. 1-8, 2014.

[26] A. Zaki, H. Kian, A. Behnia, D. G. Aggelis, J. Ying, and Z. Ibrahim, "Monitoring fracture of steel corroded reinforced concrete members under flexure by acoustic 
emission technique," Constr. Build. Mater., vol. 136, pp. 609-618, 2016.

[27] H. A. Elfergani, R. Pullin, and K. M. Holford, "Damage assessment of corrosion in prestressed concrete by acoustic emission," Constr. Build. Mater., vol. 40, pp. 925-933, 2013.

[28] A. K. M. F. Uddin, K. Numata, J. Shimasaki, M. Shigeishi, and M. Ohtsu, "Mechanisms of crack propagation due to corrosion of reinforcement in concrete by AE-SiGMA and BEM," Constr. Build. Mater., vol. 18, pp. 181-188, 2004.

[29] A. A. Abouhussien and A. A. A. Hassan, "The Use of Acoustic Emission Intensity Analysis for the Assessment of Cover Crack Growth in Corroded Concrete Structures," J. Nondestruct. Eval., vol. 35, no. 3, pp. 1-14, 2016.

[30] Y. Kawasaki, T. Wakuda, T. Kobarai, and M. Ohtsu, "Corrosion mechanisms in reinforced concrete by acoustic emission," Constr. Build. Mater., vol. 48, pp. 12401247, 2013.

[31] D. G. Aggelis, A. C. Mpalaskas, and T. E. Matikas, "Investigation of different fracture modes in cement-based materials by acoustic emission," Cem. Concr. Res., vol. 48, pp. $1-8,2013$.

[32] M. A. A. Aldahdooh and N. M. Bunnori, "Crack classification in reinforced concrete beams with varying thicknesses by mean of acoustic emission signal features," Constr. Build. Mater., vol. 45, pp. 282-288, 2013.

[33] D. G. Aggelis, S. Verbruggen, E. Tsangouri, T. Tysmans, and D. Van Hemelrijck, "Characterization of mechanical performance of concrete beams with external reinforcement by acoustic emission and digital image correlation," Constr. Build. Mater., vol. 47, pp. 1037-1045, 2013.

[34] S. Rouchier, G. Foray, N. Godin, M. Woloszyn, and J. Roux, "Damage monitoring in fibre reinforced mortar by combined digital image correlation and acoustic emission," Constr. Build. Mater., vol. 38, pp. 371-380, 2013.

[35] S. Verbruggen, S. De Sutter, S. Illipoulos, T. Tysmans, and D. G. Aggelis, "Experimental Structural Analysis of Hybrid Composite-Concrete Beams by Digital Image Correlation ( DIC ) and Acoustic Emission ( AE )," J. Nondestruct. Eval., vol. 35, no. 2, pp. 1-10, 2016.

[36] K. Ohno and M. Ohtsu, "Crack classification in concrete based on acoustic emission," Constr. Build. Mater., vol. 24, no. 12, pp. 2339-2346, 2010.

[37] IS 2185-4, "Concrete masonry units, Part 4: Preformed foam cellular concrete blocks," New Delhi, India., 2008.

[38] "RILEM FMC-50:Determination of the fracture energy of mortar and concrete by means of three - point bend tests on notched beams," Mater. Struct., vol. 18, no. 4, pp. 287290, 1985.

[39] "BS EN 14651:2005. Test method for metallic fibred concrete. Measuring the flexural tensile strength (limit of proportionality (LOP), residual)," 2005.

[40] "JAPAN CONCRETE INSTITUTE: Method of test for fracture energy of concrete by use of notched beam (JCI-S-001-2003)."

[41] A. P. Fantilli, H. Mihashi, and P. Vallini, "Post-peak behavior of cement-based materials in compression," ACI Mater. J., vol. 104, no. 5, pp. 501-510, 2007. 